\title{
Cheer-Leading versus Truth-Seeking in Intimate Relationships: Scale Development and Testing
}

\author{
By \\ Antoinette Murray \\ 300302865 \\ Supervised by Professor Garth Fletcher
}

\begin{abstract}
A thesis
submitted to the Victoria University of Wellington in fulfilment of the requirements for the degree of

Master of Science

In Psychology
\end{abstract}

Victoria University of Wellington

2014 


\section{Acknowledgements}

First of all I would like to extend my gratitude to my supervisor, Professor Garth Fletcher, who has helped me each step of the way through this year. This scale was initially his inspiration, and his guidance and willingness to answer my questions helped immensely.

Thanks to my mother, for proof-reading so many pages, so many times. Even though half the time you didn't know what you were reading, your advice and help was, and always is, greatly appreciated. Thanks especially to Teresa for help with proof-reading. To my sister and father; Joe, and my friends - thanks for listening to me bounce ideas around, and helping me when and how I needed.

Finally, I wish to acknowledge the help of Associate Professor Nickola Overall in giving me access to resources I otherwise could not have used; and Jenny, Mary, Vera and Arlene for helping with idea stimulation and formation. 


\section{CONTENTS}

$\begin{array}{ll}\text { Title page } & 1\end{array}$

Acknowledgements 2

$\begin{array}{ll}\text { Contents } & 3\end{array}$

Abstract 5

Introduction $\quad 6$

$\begin{array}{ll}\text { Study } 1 & 16\end{array}$

$\begin{array}{ll}\text { Study } 2 & 21\end{array}$

$\begin{array}{ll}\text { Study } 3 & 31\end{array}$

General Discussion $\quad 35$

$\begin{array}{ll}\text { References } & 40\end{array}$

$\begin{array}{ll}\text { Appendix } & 47\end{array}$ 
Table 1

Figure 1 20

Table 2

Table 3

Figure 2 


\begin{abstract}
This study details the development of a novel scale to measure individual differences in cheerleading (bias) and truth-seeking (accuracy) in the context of romantic relationships. In Study 1, exploratory and confirmatory factor analyses were carried out, which revealed the CheerLeading and Truth-Seeking Scale was internally reliable, and contains two distinct, albeit interrelated factors. Study 2 examined the convergent and discriminant validity of the scale. Cheerleading and truth-seeking were related to relationship quality, attachment working models, responses to dissatisfaction and conflict, self-esteem and attributional complexity in largely predicted ways. Study 3 provided evidence for the predictive ability of the scale. Cheer-leading moderated the link between relationship quality and relationship problems as predicted. That is, high levels of cheer-leading provided a buffer against decreases in relationship satisfaction in the presence of more frequent and severe problems. The implications of this research and applications of this scale are discussed.
\end{abstract}




\title{
Cheer-Leading versus Truth-Seeking in Intimate Relationships: Scale Development and Testing
}

\author{
"Truth, reason, and love keep little company together." \\ Shakespeare, A Midsummer Night's Dream.
}

Love is one of the most important themes in people's lives. It is the subject of countless books, songs and movies, and is core to most people's self-concept and life goals. This is exemplified by aphorisms such as "a life without love, is no life at all" (Leonardo da Vinci), and "the greatest thing you will ever learn is to love, and be loved in return" (Nat King Cole).

Popular notions of love include the common ideas that love is blind, and that love is a strong, uncontrollable force against which we are powerless. From an evolutionary standpoint, these beliefs ring true. The leap of faith that is required to invest and commit oneself to an imperfect other (and any possible off-spring) for a substantial period of time requires strong, biologically based emotional forces to tie us to each other (Fletcher \& Boyes, 2008; Fletcher, Simpson, Campbell, \& Overall, 2013). It is these emotions that also produce systematic positive bias of partner and relationship judgements. In short, there are good theoretical grounds for positing that people typically operate as 'cheer-leaders' in their own intimate relationships.

There is plenty of evidence to support the hypothesis that people are cheer-leaders in their own relationship. People tend to exaggerate their similarity with their partner (Murray, Holmes, Bellavia, Griffin, \& Dolderman, 2002), rate their partner as more attractive than their partner sees themselves (Barelds-Dijkstra \& Barelds, 2008), and rate their relationship as more intimate and committed, and their marriage as both better and less likely to fail, compared to others' relationships (Agnew, Loving, \& Drigotas, 2001; Fowers, Lyons, Montel, \& Shaked, 2001). 
However, there is also (seemingly contradictory) evidence that people can be remarkably accurate ('truth-seekers') when judging their partner and relationship. For example, couples are more accurate at reading the thoughts and feelings of their partner than friends or strangers are (Thomas \& Fletcher, 2003); and couples' own relationship evaluations - to a greater extent than family or friends - reliably predicts future relationship stability (MacDonald \& Ross, 1999), interaction behaviours during problem solving (Fletcher \& Thomas, 2000) and relationship dissolution (Karney \& Bradbury, 1995). Moreover, these relationship evaluations are shared across partners (Campbell, Simpson, Kashy, \& Fletcher, 2001), suggesting that both partners are tapping into a shared realistic appraisal of their relationship.

In addition, many dating and married relationships break up, indicating that the power of love has limits. From a theoretical standpoint, evolutionary theory also supports the idea that individuals should be able to accurately and reliably judge their partners and relationships. If love was completely blind, Darwinian sexual selection could not have occurred in humans. Sexual selection is based on the premise that individuals not only had choices in mating, but also made attempts to select the best mate possible. For this to occur, the process required the accurate perception of those traits most relevant and important to mate selection (Fletcher et al., 2013).

Thus we are left with an apparent paradox - people appear to be both biased and accurate in romantic relationships. How do we resolve this apparent paradox? This question will be addressed by clarifying the nature of each of the constructs, discussing some motivational forces behind each construct, and some related research findings. Finally I present the rationale behind the construction and development of a novel scale to measure individual differences in motivation - cheer-leading versus truth-seeking. 


\section{Resolving the Paradox}

Resolving the apparent paradox that love is both blind and accurate comes down to the working definitions used. Initially, the accuracy of a judgement can be defined most simply as its correspondence with reality (Fletcher et al., 2013). However, a distinction is required to clarify two independent components of accuracy: bias and tracking accuracy. Bias is defined as the mean difference between a specific judgement and its benchmark (either judgements of multiple traits from within the same couple or multiple couples judging their partner on a single trait). Tracking accuracy is the association (usually a correlation) between the judgement and benchmark (Fletcher \& Kerr, 2010). This distinction is not new, and its importance has been confirmed by several researchers recently (see for example Epley \& Dunning, 2006; Fletcher \& Boyes, 2008; Fletcher \& Kerr, 2010; Fletcher \& Kerr, 2013; Gagné \& Lydon, 2004; Kenny \& Acitelli, 2001; Lackenbauer, Campbell, Rubin, Fletcher, \& Troister, 2010).

These two components are best understood with an example. Consider the following example adapted from Fletcher and Kerr (2010; 2013). Imagine asking William to rate his wife, Kate on three traits, such as intelligence, kindness, and attractiveness, and we knew that in 'reality' Kate was a 3, 4 and 5 on each of these traits respectively (on a 7-point Likert scale where $1=$ low and $7=$ high). If William were to rate his wife as a 3,4 and 5, he would be showing high tracking accuracy and no bias, which represents the most accurate kind of judgement. If he were to rate her as a 5, 6 and 7, he would be showing positive bias, as he has rated her higher on all traits than reality, but he would have good tracking accuracy, as his ratings followed the correct pattern. If he were to rate Kate as 6, 5 and 7, he would be showing positive bias, but a low level of tracking accuracy because the pattern in reality is not reflected in his ratings.

This example clearly demonstrates how bias and tracking accuracy each constitute part of making an 'accurate' judgement, and far from being polar opposites, they can co-exist within the 
same set of judgments. Moreover, evolutionary theory provides a theoretical foundation for the importance of both kinds of judgement.

\section{Evolutionary Theory}

In pair-bonding species, such as homo-sapiens, evolutionary theory posits that biparental care increased the chance of off-spring's survival to adulthood. From this point of view, it could be argued that romantic love developed as a commitment device designed to increase the investment and bonding of not only the parents with the child, but also between the parents (Fletcher, Simpson, \& Boyes, 2006). As previously noted, the leap of faith required for such a heady investment was likely made easier by the presence of strong emotional ties and associated overly-positive and charitable perceptions of one's partner and relationship (Fletcher \& Kerr, 2010).

In a similar vein, achieving good tracking accuracy is consistent with sexual selection precepts; namely it allows individuals to select their mates in an accurate fashion, aiming for the best possible partner. Individuals would look for traits that indicated a partner would be a good parent, such as being able and willing to invest in a relationship and any resulting off-spring, as well as mates who displayed clear signs of attractiveness, health and vitality, as these individuals would be likely to produce healthier children (Fletcher et al., 2013). In fact there is an entire field of academic research dedicated to investigating people's mate selection criteria. Researchers have consistently found (across genders, countries and cultures) that people rate physical attractiveness, measures of warmth and trustworthiness (including intelligence, kindness), and status and resources as the most important criteria in evaluating potential and existing partners and relationships (Campbell et al., 2001; Fletcher, Simpson, Thomas, \& Giles, 1999; Fletcher et al., 2013). Humans would have needed to accurately perceive these vital traits so as to select for them. 


\section{Supporting Evidence}

There is plenty of evidence that people are positively biased about their partner's traits and characteristics, that people see their partner more positively than the partner sees him or herself. Moreover, people expect happy relationships to be characterised by such biases, and prefer their own partner to be positively biased (Barelds-Dijkstra \& Barelds, 2008; Boyes \& Fletcher, 2007; Murray, Holmes, \& Griffin, 1996a; Murray, Holmes, \& Griffin, 1996b). Holding positive illusions about one's partner and relationship also bodes well for the relationship, as it is related to a number of positive relationship outcomes, both concurrently and longitudinally. Positive bias is frequently associated with higher levels of relationship quality and satisfaction (Fletcher \& Kerr, 2010), lower rates of conflict and relationship-related doubts (Murray et al., 1996a; Murray et al., 1996b), more optimism about the future of the relationship (Murray et al., 1996a), as well as increased relationship stability and satisfaction over time (Murray et al., 1996a; Murray et al., 1996b; Neff \& Karney, 2005).

Furthermore, individual's self-reported levels of love, satisfaction or commitment can be used to accurately predict future relationship satisfaction and stability (Agnew et al., 2001; Karney \& Bradbury, 1995; MacDonald \& Ross, 1999). Individuals are able to accurately recall changes in their past relationship satisfaction (Karney \& Frye, 2002), and are also reasonably accurate when rating their partner's interpersonal characteristics, or their thoughts and feelings (Murray et al., 1996a; Murray et al., 1996b; Thomas \& Fletcher, 2003).

While people tend to be positively biased about their partner in a number of ways, they also often know they are biased. Some research has found that individuals can fairly accurately ascertain the amount of bias inherent in their own and their partner's perceptions of each other (Barelds-Dijkstra \& Barelds, 2008; Boyes \& Fletcher, 2007). Additionally, while people tend to recall more improvements in their relationship over time, predict rosier futures, or expect more distress post break up than they actually experience; they are still able to accurately track their 
fluctuations in satisfaction or emotional states over this same time period (Eastwick, Finkel, Krishnamurti, \& Loewenstein, 2008; Epley \& Dunning, 2006; Karney \& Frye, 2002).

Other research has experimentally manipulated the presence (or absence) of bias and accuracy in feedback ostensibly from current or potential partners. For example, Lackenbauer and her colleagues (2010) examined how participants rated the positivity and intimacy of their relationship, following fabricated partner ratings compared to their own self-ratings. The partner ratings either communicated high or low accuracy, and high positive or no bias. The authors found that while people responded equally positively to feedback that was either highly biased or highly accurate, they were most satisfied with feedback that was both verifying (accurate) and enhancing (bias) (Gagné \& Lydon, 2001; 2003; 2004; Katz \& Beach, 2000; Lackenbauer et al., 2010).

These findings indicate the two constructs (bias and tracking accuracy) can operate independently of each other. A recent meta-analysis by Fletcher and Kerr (2010) found that across 98 studies, tracking accuracy showed a robust and significant effect size $(r=.47)$. Meanlevel positive bias showed a smaller, but still significant effect size $(r=.09)$ across 48 studies. Furthermore, for the 38 studies in which both tracking accuracy and mean-level bias were measured, there was no correlation between the two kinds of effect sizes.

In summary, both empirically and theoretically, bias and tracking accuracy are independent constructs that measure different components of the overall accuracy of judgements. It is also likely that they are linked in some contexts, as they are both pro-relationship behaviours designed to help people select and keep the best possible mate, which requires a certain level of investment in the relationship. 


\section{The Function of Cheer-Leading and Truth-Seeking}

As previously noted, this research develops a scale to measure the motivational drives that may underpin the tendencies for people to produce high levels of positive bias or tracking accuracy; namely, cheer-leading versus truth-seeking. These constructs represent general tendencies that individuals have towards perceiving their partner and relationship in a rosetinted, positively biased manner and/or in an accurate and authentic way.

Both constructs work to maintain the relationship. Cheer-leading serves self-esteem needs by creating an aura of unconditional love and acceptance, which allows people to feel safer within their relationship. Research has consistently found this to be a critical factor in developing relationship happiness and security (Boyes \& Fletcher, 2007; Lackenbauer et al., 2010; Murray et al., 1996a; Murray et al., 1996b). Being the target of idealisation also helps to quell doubts and fears about the relationship, because it fosters a sense of unconditional positive regard - that one is loved and accepted by their partner regardless of their faults or imperfections (Fowers et al., 2001; Lackenbauer et al., 2010; Murray et al., 1996a; Murray, 2001). Being the target of positive bias allows one to feel more safe and secure in their commitment to the relationship, provides reassurances that the partner is invested in the relationship, and minimises the fear of relationship termination (Campbell, Lackenbauer, \& Muise, 2006; Gagné \& Lydon, 2004; Murray et al., 1996b). Being idealised makes people feel special, valuable and cared for; and simultaneously promotes the partner and relationship, while derogating potential alternatives. Thus, investment in the current relationship is enhanced and maintained (Fletcher \& Thomas, 1996).

Truth-seeking, on the other hand, is driven by more epistemic needs, and works to acknowledge and accommodate the partner's strengths and weaknesses, along with developing a realistic understanding of the partner and relationship. It may be particularly important in specific situations, such as when making an important relationship decision, or trying to understand a relationship occurrence (Fletcher \& Kerr, 2010). Both truth-seeking and tracking 
accuracy are linked to self-verification theory (Swann, De La Ronde, \& Hixon, 1994), which posits that people want their self-views to be verified, to be known and understood for who they are, and they also want to truly know their partner. These motivations foster perceptions of control and predictability within relationship interactions. Swann has argued that being verified by one's partner shows they acknowledge both your virtues and faults, and love you anyway (Campbell et al., 2006; Murray \& Holmes, 2009; Swann et al., 1994). Strongly biased partner views on the other hand, could indicate partners hold unrealistically high expectations, or are in love with only an illusion, creating the risk of rejection when partners discover the truth (Campbell et al., 2006).

\section{Predictors of Cheer-Leading and Truth-Seeking}

The two motivational sets (cheer-leading and truth-seeking) driving biased or accurate judgements may be activated in different circumstances (Fletcher et al., 2006). For example, whether people are motivated to be cheer-leaders or truth-seekers should depend on the type of judgement being made, the stage and context of the relationship, and also individual differences.

For example, Fletcher and Kerr (2010) found that while people were positively biased when judging individual-level attributes (personality traits, mind-readings, memories of the relationship, and predictions of the relationship future) the interpersonal traits - such as trust, relationship satisfaction, aggression and criticism - possessed an overall negative default bias. These authors explained this pattern of findings with error management theory (Haselton \& Buss, 2000). For example, the personal and relational costs of overestimating a partner's attractiveness are quite different to those overestimating a partner's support or forgiveness. In the latter case, overestimation could lead to complacency and a lack of relationship maintenance, which could be harmful to, or eventually erode the relationship, whereas overestimating a partner's personality traits does not hold the same kind of threat to a relationship. 
Additionally, while people generally desire honesty and authenticity in their relationships, they prefer to be idealised by their partner on traits highly relevant to dating and relationships (Fletcher et al., 1999; Kenny \& Acitelli, 2001; Murray et al., 1996a; Neff \& Karney, 2005; Swann et al., 1994). For example, Campbell (2005) found that while people prefer to receive verifying feedback from their partner on traits that were harder for outsiders to judge, such as thoughtfulness, they preferred to be enhanced on traits that were more directly observable by others, such as attractiveness.

Similarly, Neff \& Karney (2005) found the best and most lasting marriages were built on a global level of cheer-leading, which allows an abstract, overarching enhancement of their partner's qualities, but still retains an accurate understanding of their specific strengths and weaknesses. In this research, holding accurate views of specific traits, while maintaining an overall sunny disposition, resulted in a lower likelihood of relationship dissolution.

The stage of the relationship can also impact whether cheer-leading or truth-seeking is motivated. While cheer-leading is valuable at all stages of a relationship, early passion tends to push individuals into a more cheer-leading mode. Cheer-leading may be most beneficial in the early stages as it buffers partners against the fears and doubts they may have about heavily investing in each other (Campbell et al., 2006). Enhancing feedback from a new relationship partner indicates hope for the future and a decreased risk of relationship dissolution, whereas realistic appraisals of one's faults at this early stage are threatening (Swann et al., 1994; Thomas \& Fletcher, 2003). Later in the relationship, when companionate love is more dominant, and the future of the relationship is no longer in question, the threat of truth-seeking subsides (Fletcher \& Kerr, 2013). Intimates in longer-term relationships appreciate more verifying feedback from their partner as it indicates they are known, understood, and accepted, and can trust and depend upon their partner (Campbell et al., 2006). 
A contextual influence originally suggested by Fletcher and Thomas (1996), and tested by Gagné and Lydon (2001; 2004), concerns the impact of decision making, in relation to the stage of the relationship, on cheer-leading and truth-seeking motives. Making important decisions about relationships, such as whether to move in together, have children, or break up, should motivate individuals to set aside their biased perceptions, and evaluate their relationship truthfully and realistically (Fletcher \& Kerr, 2013). However once decisions have been made regarding the level of investment in the relationship, similar to cognitive dissonance resolution, cheer-leading tendencies should be amplified, to soothe fears and doubts, and to confirm it was the correct decision. Supporting this hypothesis, Gagné and Lydon (2001) found that when individuals were in a pre-decisional, objective and rational state of mind, they were more accurate in predicting the future survival of their relationship but when they were put in a postdecision mindset they were overly optimistic in their predictions.

Finally, individual differences can influence motivational orientations and the ability or desire to engage in cheer-leading or truth-seeking. For example, individuals with low self-esteem or an anxious attachment have generally negative views about themselves, their value to others and their worthiness of love. Having such negative beliefs about the self makes it harder to have positive perceptions of others, or accept their positive views of you (Collins \& Feeney, 2000; Murray et al., 1996a; Murray, Holmes, \& Griffin, 2000). Therefore, these individuals are much less likely or able to be cheer-leaders, and more likely to be truth-seekers (Murray et al., 1996b; Murray et al., 2005).

Previous research examining judgmental accuracy has typically compared judgements to external benchmarks for 'reality'. These benchmarks include the partner's relationship- or selfperceptions (e.g., Barelds-Dijkstra \& Barelds, 2008; Gagné \& Lydon, 2003), the partner's own thoughts and feelings (e.g., Overall, Fletcher, \& Kenny, 2012); ratings made by friends or family (e.g., MacDonald \& Ross, 1999); ratings made by strangers, or observational coders (e.g., 
Simpson, Oriña, \& Ickes, 2003; Thomas \& Fletcher, 2003); or experimentally manipulated feedback ostensibly from current or potential partners (e.g., Campbell et al., 2006; Lackenbauer et al., 2010). Longitudinal studies have also tracked relationship satisfaction and stability over time, comparing people's future predictions, or past recollections with actual data collected at the time (Karney \& Frye, 2002; MacDonald \& Ross, 1999; Neff \& Karney, 2005). However no measure currently exists that deals with the general motivations that drive biased or accurate judgements in romantic relationships. This study aims to remedy this situation by developing a brief scale that is reliable and valid.

\section{The Current Research}

This research had three main aims. First I intended to develop a reliable and valid scale that measured individual differences in truth-seeking and cheer-leading in romantic relationships. Second, the convergent and discriminant validity of the scale was tested. Third, some preliminary evidence was gathered concerning the predictive validity of the scale and its two factors.

Three studies were conducted. In study 1, I conducted an exploratory factor analysis to examine the internal reliability of the items and the factor structure of the scale. A confirmatory factor analysis was also conducted to further test the factorial structure. Study 2 tested the convergent and discriminant validity of the scale. Study 3 examined the predictive ability of the scale by testing the extent to which truth-seeking and cheer-leading moderated the link between relationship quality, and the severity and quantity of relationship problems.

\section{Study 1}

The Cheer-Leading and Truth-Seeking Scale was developed from an initial pool of items, into a 16 item scale with eight items for each factor, which incorporated four partner-based and 
four relationship-based questions. This scale was initially piloted with a sample of 147 university students from Victoria University of Wellington (76 female, 71 male). Statistical checks for internal reliability and an exploratory factor analysis were carried out, revealing four items that did not load satisfactorily onto their respective factors. Based on the exploratory factor analysis, two questions from each category were removed, leaving six items for each category.

\section{Method}

Participants. Study 1 participants were 513 individuals (302 female, 211 male) currently in intimate relationships. Respondents completed an online survey through the CrowdFlower website. CrowdFlower accesses the Mechanical Turk online system that is increasingly being used for research surveys. Participants are based in many countries, and are paid a small amount of money for survey completion.

Of these 513 participants, 444 were in heterosexual relationships, 67 were in same-sex relationships, and 2 individuals did not state their partner's gender. Of this sample, $32.4 \%$ of couples were dating, $23.2 \%$ were living together, and $44.4 \%$ were married. Their ages ranged from 18 to 67 years $(\mathrm{M}=33.71, \mathrm{SD}=11.12)$ and mean relationship length was 7.85 years $(\mathrm{SD}=$ 9.04). Participants were from a range of countries, 4 from NZ, 4 from Australia, 72 from the UK, 105 from Canada and 328 from the USA.

Procedure. Participants were asked to rate their level of agreement with the 12 item scale shown in Table 1 and the appendix (e.g., "I always see the bright side when thinking about my relationship", and "I often analyse my relationship"), on a 7-point Likert scale where $1=$ strongly disagree, and $7=$ strongly agree. 


\section{Results}

Exploratory factor analysis. Initially, an exploratory factor analysis (principlecomponents analysis with oblique Kaiser rotation) was conducted on the 16 item scale which replicated the same pattern of results as the pilot test. The same 4 items did not load adequately onto their respective factors; thus all subsequent analyses presented here are based on the 12 item scale.

An exploratory factor analysis (principle components with oblique Kaiser rotation) was conducted on the final 12 item scale. As expected, a two factor solution provided the best fit, according to the scree test and eigenvalues. The unrotated eigenvalues were 6.0 and 1.7 , with no other factors having eigenvalues over 1.0, and these two factors accounted for $64.1 \%$ of the variance. Additionally, the rotated eigenvalues were 5.2 and 4.7. As can be seen in Table 1, all variables loaded strongly and positively onto their respective factors, with low loadings on the other factor. This suggests there are two clear-cut factors.

The internal reliability analysis confirmed the factor analysis results. The corrected itemtotal correlations, as well as the means, standard deviations, and factor loadings for each of the items are shown in Table 1. Each of the two factors showed good internal reliability with strong, positive item-total correlations. Cheer-leading had loadings that ranged between .64 and .78, with a Cronbach's alpha of .90, while truth-seeking's loadings ranged from .61 to .74 , with an alpha of .87 . 
Table 1

Means, Standard Deviations, Factor Loadings and Item-Total Correlations for the Cheer-

Leading and Truth-Seeking Scale.

\begin{tabular}{|c|c|c|c|c|c|}
\hline \multirow[t]{2}{*}{ Scale items } & \multirow[t]{2}{*}{ M } & \multirow[t]{2}{*}{ SD } & \multirow{2}{*}{$\begin{array}{l}\text { Item-total } \\
\text { correlation }\end{array}$} & \multicolumn{2}{|c|}{ Factor Loading } \\
\hline & & & & $\begin{array}{c}\text { Factor } \\
1\end{array}$ & $\begin{array}{c}\text { Factor } \\
2\end{array}$ \\
\hline \multicolumn{6}{|l|}{ Cheer-Leading } \\
\hline $\begin{array}{l}\text { I always see the bright side when thinking } \\
\text { about my relationship }\end{array}$ & 5.44 & 1.40 & .75 & .84 & -.01 \\
\hline I avoid negative thinking about my partner & 5.15 & 1.49 & .70 & .82 & -.05 \\
\hline $\begin{array}{l}\text { I try to think positively about my } \\
\text { relationship }\end{array}$ & 5.73 & 1.24 & .78 & .82 & .08 \\
\hline I am an optimist about my relationship & 5.58 & 1.34 & .74 & .84 & -.01 \\
\hline $\begin{array}{l}\text { I prefer to focus enjoying on my partner's } \\
\text { company, rather than dwell on bad things }\end{array}$ & 5.68 & 1.22 & .75 & .82 & .03 \\
\hline $\begin{array}{l}\text { I try to forget about negative things in my } \\
\text { relationship }\end{array}$ & 5.21 & 1.44 & .64 & .70 & .07 \\
\hline \multicolumn{6}{|l|}{ Truth-Seeking } \\
\hline I try hard to understand my relationship & 5.45 & 1.36 & .66 & .28 & .59 \\
\hline $\begin{array}{l}\text { I try hard to explain problems in our } \\
\text { relationship }\end{array}$ & 5.23 & 1.44 & .61 & .10 & .66 \\
\hline $\begin{array}{l}\text { I always want to know what my partner is } \\
\text { thinking and feeling about me }\end{array}$ & 5.13 & 1.48 & .73 & .03 & .83 \\
\hline I often analyse my relationship & 4.77 & 1.58 & .62 & -.21 & .88 \\
\hline $\begin{array}{l}\text { I always like to know what my partner } \\
\text { thinks about our relationship }\end{array}$ & 5.14 & 1.46 & .74 & .02 & .84 \\
\hline $\begin{array}{l}\text { I want to know the truth about our } \\
\text { relationship }\end{array}$ & 5.73 & 1.36 & .63 & .17 & .64 \\
\hline
\end{tabular}

Confirmatory factor analysis. All confirmatory factor analyses were done using IBM SPSS Amos Graphic version 20.0.0. To reduce the number of variables for the analysis, the six items within each component (cheer-leading and truth-seeking) were combined to create three 
observed variables, by summing and averaging the first two items together, the third and fourth, and finally fifth and sixth items.

Levels of fit were assessed using the significance levels of the chi-square, the comparative fit index (CFI), and the root mean square error of approximation (RMSEA). The CFI is generally regarded as a better indicator of fit than statistical significance, as it is not adversely affected by sample size, whereas statistical significance is acutely sensitive to large samples. A CFI above .90 indicates a good fit. (Bentler, 1995; Marsh, Balla, \& McDonald, 1988). The RMSEA provides a measure of discrepancy per degree of freedom, and a value of 0.8 or less indicates reasonable fit.

I first tested a two factor model (shown in Figure 1) with three observed variables loading on to each of the two unobserved factors, allowing for the two factors to be correlated. The loadings for each observed variable onto their respective factors are shown in Figure 1, and ranged from .73 to .92 . The inter-factor correlation was moderately high at .65 , and the CFI indicated a good fit with a value of .98 , and the RMSEA was .11 (slightly above the recommended .08$), X^{2}(8, N=513)=48.03, p<.001$.

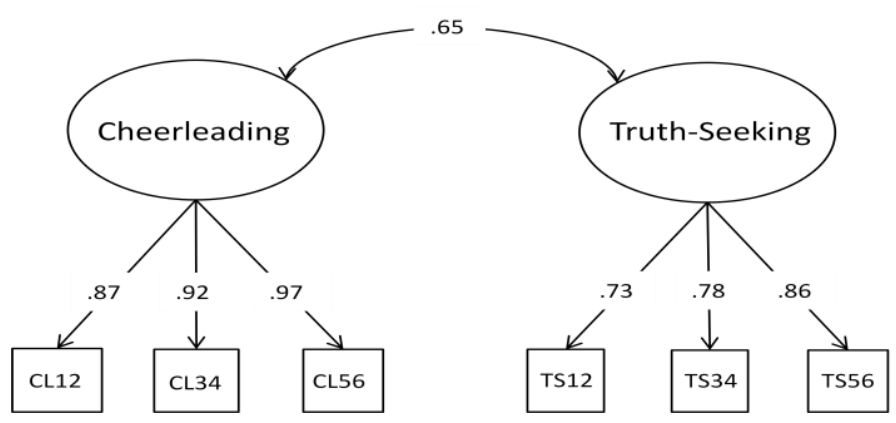

Figure 1. The two-factor model of cheer-leading and truth-seeking tested in the confirmatory factor analysis.

I also tested a one factor model with all six observed variables loading onto a single factor. This model showed a poor fit, with an RMSEA of .27 (well above the recommended .08), and a 
CFI of .81 (under the recommended .90$), X^{2}(9, N=513)=336.24, p<.001$. The Chi-square difference in fit between this model and the two-factor model was substantial; $\Delta X^{2}(1, N=513)=$ 288.21, $p<.001$ Thus, as expected, the two-factor model provided a better solution that the onefactor model.

Gender. No significant gender differences were found in the analyses of cheer-leading or truth-seeking in our sample, and thus gender is not discussed further.

\section{Discussion}

To summarise, the data supported my prediction that the Cheer-Leading and Truth-Seeking Scale contains two correlated, but independent factors. The results from the exploratory factor analysis clearly indicated the existence of two separate factors that were reliable and internally consistent. This finding was replicated and confirmed by the confirmatory factor analysis. Although there was a moderate level of inter-factor correlation in the two-factor model, the results clearly showed this model had much better fit than the one factor model.

\section{Study 2}

In this study I examined the convergent and discriminant validity of the Cheer-Leading and Truth-Seeking Scale. Various scales were completed and the associations between these scales and the Cheer-Leading and Truth-Seeking Scale were assessed. 


\section{Convergent Validity}

Generally, people who are happier with their relationships engage in more pro-relationship behaviours, are more invested, and more interested in maintaining their relationships. Additionally, it is consistently found that people who exhibit higher levels of positive bias, or cheer-leading, in their appraisals of their partner are found to be happier and report higher levels of relationship quality, both in the short-term and in the long-term (Campbell et al., 2006;

Fletcher \& Kerr, 2010; Fowers et al., 2001; Murray et al., 1996a; Murray et al., 1996b; Neff \& Karney, 2005). Thus I expected to find a positive correlation between relationship quality and cheer-leading.

Anxiously attached individuals are preoccupied with a fear of rejection and feel unworthy of love, making them needy. In contrast, avoidantly attached individuals prefer to be independent and avoid intimacy (Collins \& Feeney, 2000; Simpson et al., 2011). Therefore, I predicted that both anxious and avoidant attachment styles would be negatively correlated with cheer-leading tendencies, as anxiously attached individuals hold negative self-views, and are too fearful to be able to maintain such blindly positive partner-views; and avoidant individuals feel uncomfortable engaging in positive thinking about their partner (Simpson et al., 2011). I also predicted anxious attachment would be positively correlated with truth-seeking, as these individuals fear abandonment and are hypervigilant to signs of rejection. They should thus be constantly analysing their partner's behaviours, and be sensitive to changes in their partner's regard (Overall et al., 2012).

Self-esteem is a measure of one's feelings of self-worth, an emotional and cognitive evaluation of one's competence and value. I predicted self-esteem would have a positive relationship with cheer-leading. Low self-esteem is associated with negative self-perceptions and insecurities that make it harder to hold positive views of others. These self-doubts, and feelings that the responsiveness of others is conditional, are presumably linked to having doubts about the 
relationship (Murray et al., 1996a; Murray et al., 2000). Conversely, increased feelings of selfworth should enable individuals to have more positive partner- and relationship-based views.

Attributional complexity represents the tendency to produce and prefer complex explanations for human behaviour. This includes making more abstract and external attributions for both the self and others, inferring more complex causes or explanations, and having more meta-awareness of the underlying process involved in attributions (Fletcher, Danilovics, Fernandez, Peterson, \& Reeder, 1986). This dispositional tendency was predicted to have a positive relationship with truth-seeking, given that truth-seeking measures the tendency or desire to analyse and interpret partner's thoughts and feelings.

Finally, the exit-voice-loyalty-neglect (EVLN) typology (Rusbult \& Zembrodt, 1983; Rusbult, Zembrodt, \& Gunn, 1982) measures the tendency to react actively or passively, and constructively or destructively in response to partner transgressions. It was predicted that cheerleading would be negatively correlated with active and destructive 'exit' tendencies, as those with positively biased perceptions of their partner believe the best in their partner, and thus are either more willing, or more able to brush over negative events. These individuals would be unlikely to consider ending the relationship following one negative interaction. Cheer-leading should on the other hand, be positively correlated with the constructive behaviours of 'voice' and 'loyalty'. Loyalty involves forgiving and forgetting transgressions, something cheer-leaders would do naturally, as they prefer to focus on positive instances within their relationship, and voice refers to openly discussing problems in a constructive manner with the intent of improving conditions. Cheer-leaders are likely to engage in more of these positive, pro-relationship behaviours because they perceive their relationship to be highly satisfying and enduring in general, and these constructive conflict tactics are likely to reduce the negative impact of conflict on the relationship (Overall, Sibley, \& Travaglia, 2010). 


\section{Discriminant Validity}

Along with the convergent correlations, I predicted a set of null correlations. Cheer-leading was predicted to have little or no association with either attributional complexity, or neglect tendencies; and truth-seeking was expected to have no relationship with ratings of relationship quality, attachment avoidance, self-esteem, nor any of the EVLN factors.

\section{Method}

Participants and Procedure. Participants were 176 individuals ( 94 female, 82 male) currently in romantic relationships, again contacted though the CrowdFlower website. This sample included 153 heterosexual individuals, 22 homosexual individuals, and 1 participant who did not state their partner's gender. In this sample, $44.9 \%$ were dating, $20.5 \%$ were living together, and the remaining $34.7 \%$ were married. Participants ages ranged from 18 to 67 years $(\mathrm{M}=32.51, \mathrm{SD}=10.99)$, and mean relationship length was 6.43 years $(\mathrm{SD}=7.98)$. Participants were from a range of countries, 1 from NZ, 3 from Australia, 18 from the UK, 40 from Canada and 114 from the USA.

Participants anonymously completed a series of questionnaires online that measured various aspects of their relationships and themselves, including relationship quality, attachment orientations, conflict style, self-esteem and the complexity of their attributions. All of the scales used are shown in the appendix.

\section{Measures.}

Cheer-leading and truth-seeking. Participants completed the 12 item scale from study 1 (Cronbach's alpha $=.93$ for cheer-leading, and .90 for truth-seeking).

Attachment. Attachment orientations were measured using the Adult Attachment Questionnaire (AAQ; Simpson, Rholes, \& Phillips, 1996). Anxiety items measured participant's 
concern for abandonment (e.g., "I often worry that my partner doesn't really love me", $1=$ strongly disagree, 7 = strongly agree), and avoidance items measured the degree to which participants avoid intimacy and closeness (e.g., "I'm not comfortable having to depend on my romantic partners", 1 = strongly disagree and 7 = strongly agree). Items from each scale were scored and averaged so that higher scores represented higher levels of anxious attachment $($ Cronbach's alpha $=.78)$ and attachment avoidance (Cronbach's alpha $=.74)$.

Relationship quality. Participant's relationship quality was measured using the short (6 item) version of the Perceived Relationship Quality Components Inventory (PRQC; Fletcher, Simpson, \& Thomas, 2000) which has demonstrated reliability and validity in prior research. Participants were asked to rate how 'satisfied', 'committed', 'intimate' and 'passionate' their relationship was, and how much they 'love' and 'trust' their partner, on a 7-point Likert scale where $1=$ not at all, and $7=$ extremely $($ Cronbach's alpha $=.93)$. Higher scores represented higher reported relationship quality.

Exit-voice-loyalty-neglect (EVLN) typology. Participant's typical responses to relationship problems or dissatisfaction were measured using the EVLN Typology (Rusbult \& Zembrodt, 1983; Rusbult et al., 1982) on a 7-point Likert scale where $1=$ never do this, $4=$ sometimes do this, and $7=$ constantly do this. The four classes of behaviour are exit (threatening or ending the relationship), voice (openly discussing the issue), loyalty (patiently holding one's tongue), and neglect (neglecting relationship care). Example items include: for exit "When I'm unhappy with my partner, I consider breaking up" (Cronbach's alpha $=.86)$, voice "When my partner is upset and says something mean, I try patch things up and solve the problem" (Cronbach's alpha $=.84)$, loyalty "When my partner behaves in an unpleasant or thoughtless manner, I forgive my partner and forget about it" (Cronbach's alpha = .78), and neglect "When my partner is upset and says something mean, I sulk and try to stay away from my partner for a 
while" (Cronbach's alpha =.76). Items were scored and averaged so higher scores represented more use of that tactic.

Attributional complexity. A short version of the Attributional Complexity Scale (Fletcher et al., 1986) was used to measure the complexity of participant's causal attributions (e.g., "I often think about the different ways that people influence each other", 1 = strongly disagree and $7=$ strongly agree). The shortened scale (where 28 items were reduced to 7), as shown in the appendix, has been shown to adequately represent the full scale (Fletcher \& Kerr, 2010), and higher scores indicate more complex attributions (Cronbach's alpha $=.86$ ).

Self-esteem. Participant's global feelings of self-worth were measured using the Rosenberg Self-Esteem Questionnaire (SEQ; Rosenburg, 1965). Participants were asked to rate their level of agreement with 10 statements such as "I feel I have a number of good qualities", on a 7-point Likert scale where $1=$ strongly disagree and $7=$ strongly agree. Higher scores indicated higher levels of global self-esteem (Cronbach's alpha $=.85)$.

\section{Results}

Multiple regression analysis. Cheer-leading and truth-seeking scores attained a moderately high correlation $(r=.56)$. Thus, to examine the convergent and discriminate validity of our scale, I carried out multiple regressions in which the variables of interest were regressed on both cheer-leading and truth-seeking scores. The results are shown in Table 2. 
Table 2

Standardised Beta Weights Regression Values where Cheer-Leading and Truth-Seeking were the Independent

Variables and all Other Scales, and Sub-Scales were the Dependant Variables.

\begin{tabular}{ccccccccccc}
\hline & \multicolumn{10}{c}{ Dependant Variables } \\
\cline { 2 - 9 } $\begin{array}{c}\text { Independent } \\
\text { Variables }\end{array}$ & $\begin{array}{c}\text { Relationship } \\
\text { Quality }\end{array}$ & $\begin{array}{c}\text { Attachment } \\
\text { Anxiety }\end{array}$ & $\begin{array}{c}\text { Attachment } \\
\text { Avoidance }\end{array}$ & E & V & L & N & $\begin{array}{c}\text { Attributional } \\
\text { Complexity }\end{array}$ & $\begin{array}{c}\text { Self- } \\
\text { Esteem }\end{array}$ \\
\hline Cheer-Leading & $\mathbf{. 4 5}$ & $\mathbf{- . 2 0}$ & $\mathbf{- . 3 0}$ & $\mathbf{- . 2 4}$ & $\mathbf{. 4 3}$ & $\mathbf{. 5 3}$ & -.03 & $\mathbf{. 2 3}$ & $\mathbf{. 2 3}$ \\
Truth-Seeking & .08 & $\mathbf{. 2 6}$ & .16 & $\mathbf{. 3 9}$ & .01 & -.06 & $\mathbf{. 2 5}$ & $\mathbf{. 3 7}$ & -.09 \\
\hline
\end{tabular}

Note. Correlations that are significant at the $p<.05$ level are in bold type. 
Convergent validity. Consulting the beta weights, all 9 convergent predictions were correct. Cheer-leading was associated with significantly higher levels of voice and loyalty, reported relationship quality, and self-esteem. Higher cheer-leading was also associated with lower levels of attachment anxiety, attachment avoidance and exit behaviours. This confirms that those who engage in more cheer-leading behaviours are more satisfied within their relationship, have higher self-esteem, lower levels of anxiety about their partner abandoning them, and generally more positive relationship perceptions. Cheer-leaders also reported utilising more constructive conflict behaviours that focus on repairing and maintaining the relationship, and fewer negative, destructive behaviours. Additionally, more truth-seeking was linked to higher attributional complexity and anxious attachment, indicating those who are hypervigilant to signs of rejection tend to also be more analytical in their relationships, as expected.

The moderately sized beta weights ranged from .20 to .53 indicating that although similarities exist between the two constructs and the comparison scales used, the Cheer-Leading and Truth-Seeking Scale does, in fact, measure different and unique constructs.

Discriminant validity. Of the 9 discriminant predictions, 6 were correct. As expected, cheer-leading showed no relationship with neglect tendencies, and truth-seeking was not related to relationship quality, avoidant attachment, voice, loyalty, or self-esteem. These results illustrate the cheer-leading and truth-seeking constructs do not simply measure individual's self-esteem or conflict tactics, nor their attachment to, and satisfaction with their partner.

However, while I predicted no link between truth-seeking and both exit and neglect, and no relationship between cheer-leading and attributional complexity, and I found these to have significant, positive relationships. Thus, people who truth-seek more within their relationship were also more likely to let the relationship atrophy, or consider leaving their partner after negative interactions; and more cheer-leading was linked to more complex attributions. 


\section{Discussion}

Of the 18 predictions, 15 were confirmed. Higher cheer-leading was associated with better relationship quality, more secure attachment, higher self-esteem, greater use of the constructive conflict behaviours, and fewer exit behaviours. Truth-seeking was not related to these variables, but was linked to higher attachment anxiety, and more complex attributions, as was expected. However there were three unexpected positive relationships. Truth-seekers engaged in more exit and neglect behaviour during conflicts, and cheer-leaders reported more attributional complexity. Possible explanations for these findings are discussed below.

Truth-seeking, exit, and neglect. Null relationships were initially predicted between truth-seeking and exit, and truth-seeking and neglect. Only one prior study to my knowledge has examined bias and accuracy within a conflict situation (Overall et al., 2012). However the interest in this study was how the threat inherent in conflict situations might influence both more accurate tracking, and under-estimations of a partner's regard. No previous research has examined how behaviour during conflict relates to general relationship-focused cognitive styles, such as truth-seeking.

Rusbult and colleagues' (1982; 1983) EVLN typology was designed to describe how individuals respond to dissatisfaction and conflict within their relationships. Responses can fall along two dimensions, active vs passive, and constructive vs destructive. The categorisation of responses depends on the behaviour's impact on the problem and relationship, and is not necessarily a description of the behaviour itself. Exit and neglect are destructive behaviours as they are not intended to maintain or repair the relationship. Neglect entails passively allowing the relationship to deteriorate, through ignoring, criticising, or spending less time with the partner, treating the partner or relationship badly, and refusing to discuss problems. Exit, on the other 
hand, is more active, and involves actually ending the relationship, separating, moving out or divorcing (Rusbult, Johnson, \& Morrow, 1986).

While the significant and positive relationship found between truth-seeking and these two conflict behaviours was unpredicted, it is not surprising in retrospect. The occurrence of problems within relationships instigates the production of more (and usually negative) attributions for partner's behaviour, and negative attributions are also likely to increase the instances of negative conflict behaviour (Murray et al., 2000). In the heightened emotional state that occurs during conflict, individuals may be more disposed to question their relationship's future. Given that truth-seekers tend to more routinely analyse their relationship, they may be even further prone to questioning their relationship's validity and future when they are dissatisfied. These doubts may result in the inclination to engage in more exit and neglect behaviours, such as allowing the relationship to run its natural course, rather than make active efforts at repair. This explanation is consistent with some of the early attributional studies showing that attributional activity and time spent analysing behaviour were more pronounced when relationships were more conflictual, or when individuals were thinking more about leaving their partner (Fletcher, Fincham, Cramer, \& Heron, 1987).

Work done by Gagné and Lydon (2003; 2004) shows that truth-seeking can be used to relatively objectively assess one's relationship. Perhaps individuals experiencing higher levels of conflict are motivated to truth-seek more in order to more accurately assess their compatibility with their partner, and the future potential of the relationship.

Cheer-leading and attributional complexity. The significant positive relationship found between cheer-leading and attributional complexity was unanticipated. It could, of course, be a chance finding. However it may be due to the mechanisms through which cheer-leading works. Cheer-leaders maintain their rose-tinted view through constantly making positive and benevolent attributions of their partner and relationship. They are optimists who choose to see and focus on 
the bright side of things, while minimising negative experiences. It is well known that benevolent cognitions involve making external, unstable and benign attributions for negative partner behaviours that do not fit with a generally positive attitude towards one's partner (McNulty, O'Mara, \& Karney, 2008). Perhaps cheer-leading works in a similar way; thus cheerleaders may be doing substantial amounts of attributional work in their day-to-day lives, and thus are more attributionally complex, at least on this dimension.

In summary, the pattern of results found across both convergent and discriminant testing provides evidence that the Cheer-Leading and Truth-Seeking Scale has reasonable construct validity and thus may usefully predict other variables.

\section{Study 3}

In this study I tested my prediction that cheer-leading would moderate the link between the extent of relationship problems and relationship quality. Overall, lower relationship quality should be associated with more problems being reported by intimate partners. However, I expected high levels of cheer-leading to buffer this association, such that high levels of cheerleading should reduce the link between relationship satisfaction and the incidence of relationship problems. In contrast, low levels of cheer-leading should produce a stronger link between having more problems and reporting lower levels of relationship satisfaction. In addition, to add some discrimant validity, I predicted that truth-seeking would not exert a moderating impact on this link between the number of relationship problems and relationship satisfaction. 


\section{Method}

Participants and procedure. The participants in this study were the same subjects as those in Study 1. Following the completion of the Cheer-Leading and Truth-Seeking Scale, participants additionally completed surveys measuring their relationship quality, and the extent of problems within their relationship.

\section{Measures.}

Relationship problems. The severity of problems within participant's relationships was measured using the Marital Problems Inventory (Geiss \& O'Leary, 1981). Participants were asked to rate 25 items which represent common points of disagreement within relationships according to the degree of difficulty experienced within their relationship (e.g., 'communication', 'children', 'showing affection', on a Likert scale where $1=$ not a problem and $7=$ major problem). Items were scored and averaged so that higher scores represented more severe problems (Cronbach's alpha $=.96)$.

Cheer-leading and truth-seeking. Participants completed the 12 item scale from study 1 (Cronbach's alpha $=.90$ for cheer-leading, and .87 for truth-seeking).

Relationship quality. Participant's relationship quality was again measured using the 6 item PRQC (Fletcher et al., 2000) as in study 2 (Cronbach's alpha = .93).

\section{Results}

I hypothesised that the link between relationship problems and relationship quality would be moderated by cheer-leading, but not by truth-seeking. In other words, relationship quality is likely to decrease overall when more problems exist within the relationship, but I predicted this decrease in satisfaction would be less pronounced for those high in cheer-leading, as opposed to 
those who engaged in low levels of cheer-leading. I predicted that no such moderating effect would occur for truth-seeking.

To test these predictions, I calculated a hierarchical regression analysis with relationship quality as the dependent variable. The results of this analysis are shown in Table 3 . In the first stage of the analysis, cheer-leading, truth-seeking and problems (all centred) were entered as predictors. As can be seen, all three variables had significant main effects. Happier participants were more engaged in both cheer-leading $(t=13.54, p<.001)$ and truth-seeking behaviours $(t=$ $4.39, p<.001)$, and reported fewer relationship problems $(t=-9.18, p<.001)$.

The interaction terms were then included in stage 2 of the analysis, and as expected, the interaction between cheer-leading and problems was significant $(t=3.28, p=.001)$, controlling for truth-seeking. However, the interaction between truth-seeking and problems was not significant when controlling for the effect of cheer-leading.

Table 3

Hierarchical Multiple Regressions Testing the Moderating Effects of Cheer-Leading and TruthSeeking on the Association Between Relationship Problems and Relationship Satisfaction (as the Dependent Variable).

\begin{tabular}{|c|c|c|c|}
\hline & $\begin{array}{l}\text { Zero Order } \\
\text { Correlations }\end{array}$ & $\begin{array}{c}\text { B (Beta } \\
\text { weights) }\end{array}$ & $\mathrm{t}$ \\
\hline Cheer-Leading & .73 & .51 & 13.54 \\
\hline Truth-Seeking & .50 & .15 & 4.39 \\
\hline Problems in Relationship & -.55 & -.29 & -9.18 \\
\hline Multiple R & .78 & & \\
\hline \multicolumn{4}{|l|}{ Stage 2} \\
\hline Cheer-Leading X Problems & & .13 & 3.28 \\
\hline Truth-Seeking X Problems & & .02 & .54 \\
\hline Multiple R & .79 & & \\
\hline
\end{tabular}


The significant interaction is shown in Figure 2. Although there was a general decline in relationship quality when higher levels of relationship problems were reported, higher levels of cheer-leading provided a buffer against this decrease in reported relationship quality.

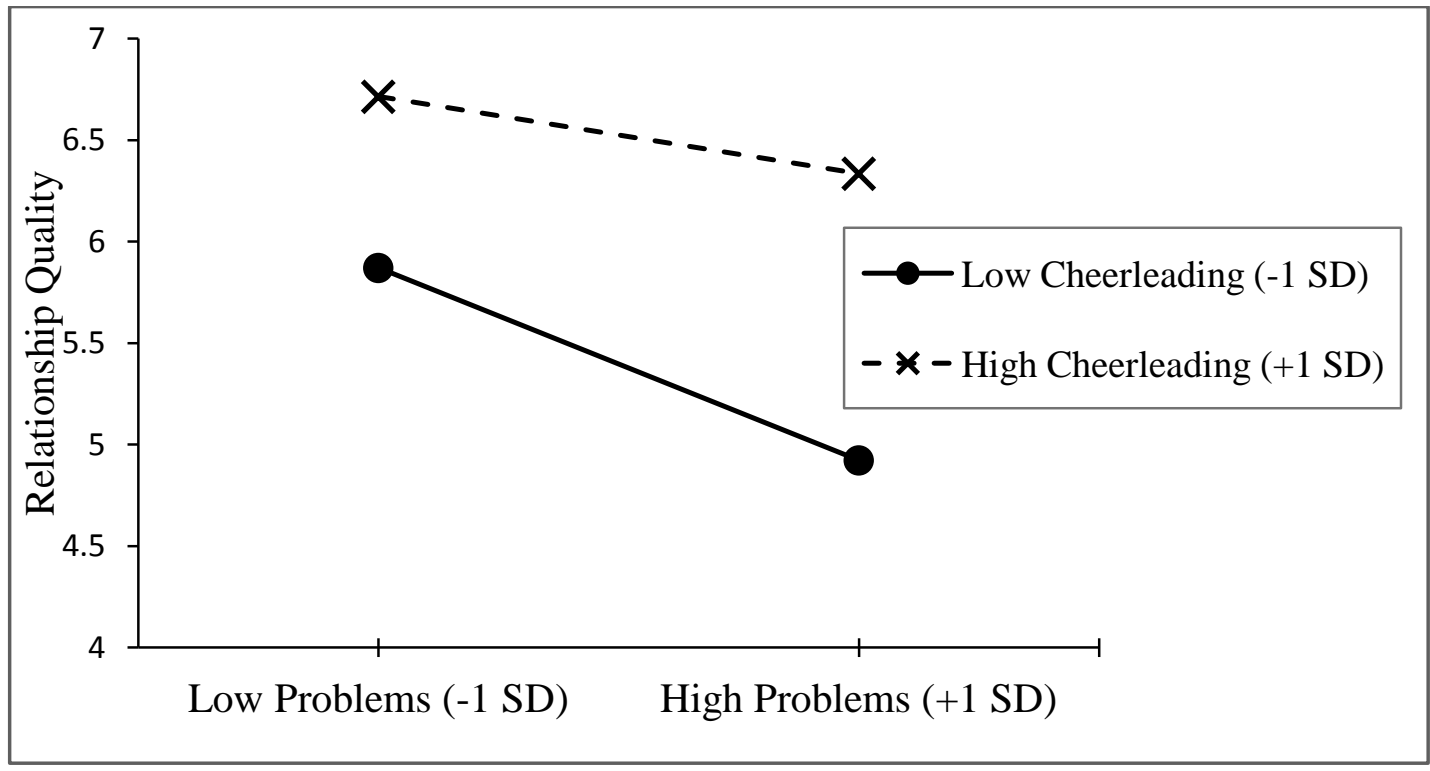

Figure 2. Graph showing the moderating effect of cheer-leading on the link between relationship problems and relationship quality.

\section{Discussion}

I tested and found support for my hypothesis that cheer-leading moderates the link between relationship problems and relationship quality. There was a main effect such that as problems in the relationship increased, relationship quality tended to decrease. However this main effect was moderated by the level of cheer-leading. More specifically, people high in cheer-leading were more protected against such a decrease in relationship quality, whilst those low in cheer-leading were less protected. Therefore, it appears high levels of cheer-leading confers benefits even during troubled times through protecting individuals from the negative impact of relationship problems. Furthermore, truth-seeking had no such moderating effect, as expected, providing further discriminant validation for the scale. 


\section{General Discussion}

The current study aimed to develop a novel psychometric tool that was both valid and reliable. This scale was intended to measure individual differences in the motivation to perceive one's partner and relationship in an overly positive, 'rose-tinted' way, and/or to see the relationship rationally and accurately. Three studies were conducted, which tested the psychometric qualities of the scale, the construct validity and some provisional predictive validity. In general, the results of this research were consistent with predictions, and provided substantial support for the internal and external validity of the Cheer-Leading and Truth-Seeking Scale.

The results of study 1 showed the scale had adequate internal reliability, with strong positive item-total correlations and factor loadings. The results of the exploratory factor analysis indicated there were two distinct factors, despite some degree of overlap. The confirmatory factor analysis confirmed that a two-factor model fit the data considerably better than a single factor.

Study 2 tested the convergent and discriminant validity of the scale. The pattern of results indicated good construct validity. As predicted, people who engaged in more cheer-leading also reported engaging in more voice and loyalty, had higher self-esteem, higher relationship quality, and were less likely to be insecurely attached or use exit-type responses. Also consistent with predictions, increased truth-seeking was related to more anxious attachment, and higher levels of attributional complexity. As expected, there were no associations between truth-seeking and relationship quality, voice, loyalty, self-esteem and avoidant attachment; nor was there an association between cheer-leading and neglect behaviours.

Against predictions, however, more truth-seeking was associated with greater reported use of both exit and neglect strategies during conflict interactions. I suggested this may be due to truth-seekers questioning and assessing the future of their relationship, and being motivated to 
allow the relationship run its course, rather than trying to repair or maintain it. Also against predictions, cheer-leading was positively related to attributional complexity. It is possible this is a chance finding, or it may be due to the frequency of benevolent attributions that cheer-leaders make, making them more prone to scoring more highly on the attributional complexity scale.

Study 3 provided some preliminary evidence for the predictive ability of the CheerLeading and Truth-Seeking Scale, and some further discriminant validity. As expected, cheerleading (but not truth-seeking) moderated the relationship between the extent of problems within the relationship, and relationship quality. The results revealed that those high in cheer-leading were more protected from declines in satisfaction when there were numerous or severe problems reported within relationships, than those low in cheer-leading. This finding supports previous similar research that posits positively biased thinking, or cheer-leading, can provide short-term relief from distress and dissatisfaction. Holding these positive attitudes allows individuals to focus on the positives of the relationship, whilst also minimising the effects of immediate negative experiences. However, in the long-term, this strategy of 'forgiving and forgetting' relationship problems can reduce the motivation to address and resolve issues, allowing them to fester over time. This can result in disillusionment and greater decreases in relationship satisfaction later in the relationship if the problems are serious (McNulty et al., 2008).

\section{Study Strengths}

The results of this research both support and extend previous work in the area of bias and accuracy within romantic relationships. My findings confirm that cheer-leading in the short-term can protect individuals from the negative effects of relationship problems, which supports the work by McNulty and his colleagues (2008) discussed above. Additionally, it is well documented that people who are more positively biased are in happier relationships, and people in fact expect happy relationships to be characterised by elements of such bias (Boyes \& 
Fletcher, 2007; Campbell et al., 2006; Fletcher \& Kerr, 2010). The current research yet again confirmed the positive link between cheer-leading and greater relationship satisfaction.

Additionally, the findings replicated previous similar work on attachment, self-esteem, bias and accuracy. Individuals low in self-esteem and attachment security tend to hold negative selfand other-expectations, which limits their ability to be positively biased about others, and to accept the biased views others have of them (Collins \& Feeney, 2000; Murray et al., 2000). Consistently higher cheer-leading was linked to increased attachment security and self-esteem, whereas truth-seeking was positively related to anxious attachment. Anxious individuals feel unworthy of love and are constantly on the look-out for signs of rejection, and thus are more motivated and better at tracking changes in their partner's regard (Murray et al., 1996a; Murray et al., 1996b; Overall et al., 2012; Simpson et al., 2011). Both truth-seeking and cheer-leading were also found to be positively related to attributional complexity, indicating these behavioural tendencies are associated with more complex mental schemas.

Finally, this research also examined how truth-seeking or cheer-leading tendencies can affect conflict interactions using the EVLN scale. This topic was previously unstudied. The results revealed that cheer-leading is associated not only with happier perceptions of relationships, but also more positive conflict behaviour; whereas truth-seeking is associated with less charitable behaviour and less positive relationship outcomes. This is an avenue future researchers should explore - examining how these tendencies affect individual's actual behaviour during conflict and the ensuing aftermath.

\section{Caveats and Future Directions}

While this work has a number of strengths, there are nonetheless a few limitations that deserve discussion. While Fletcher \& Kerr (2010) found bias and accuracy to be independent and uncorrelated; my results revealed a moderately sized correlation of .56 between cheer-leading and truth-seeking. This indicates that the motivations driving biased and accurate judgements, 
namely cheer-leading and truth-seeking, are linked by some underlying function. Perhaps this third missing factor is the extent to which people are psychologically invested in their relationships. Individuals who are highly invested are likely to be more motivated to maintain or promote their relationship through engaging in more pro-relationship behaviours. This motivation can be manifested in terms of either or both cheer-leading and truth-seeking. Thus highly invested individuals utilise more cheer-leading and truth-seeking, whereas less invested individuals lack the motivation to engage in these effortful tendencies.

A second limitation is that this research did not include a study of test-retest reliability. This was due to the nature of the sample used, as there would have been difficulty in trying to get the same sample population to complete the scale twice via Mechanical Turk. However, the benefits gained by using Mechanical Turk outweigh this issue, as it provided access to a large and international sample of respondents, allowing the results of this study to be easily generalised across many western countries. The sample also included homosexual couples, although they were not analysed separately. It would be valuable for future research to further examine the responses of homosexual couples to this scale.

Another limitation of this research is that the responses of only one partner were collected. While this is necessary for accurate scale development, it limits the conclusions that can be drawn about the way bias and accuracy work within a relationship. Future research should consider how the tendencies of each partner affect the dynamics and interactions of the dyad. Future studies that apply the scale to both members of the dyad will enable examination of the extent to which cheer-leading and truth-seeking are actually linked to bias and tracking accuracy within existing relationships.

Similar to attachment working models, it makes sense that bias- or accuracy-driven tendencies should remain fairly stable over time, while still having the potential for change depending on one's current situation, and intimate partner (see Mikulincer, Shaver, \& Pereg, 
2003). Previous research has found that the situational context can impact whether a biased or accurate judgement is motivated (e.g., Campbell et al., 2006; Fletcher \& Kerr, 2010; Gagné \& Lydon, 2004; Neff \& Karney, 2005), but longitudinal research should be undertaken to examine whether people have a "baseline" level of either motivation (cheer-leading or truth-seeking) across situations and interactions. Longitudinal research would also enable examination of the extent to which cheer-leading and truth-seeking are responses to relationship interactions and outcome attitudes versus being causes of relationship processes and outcomes.

The present study provides preliminary evidence for a novel scale that has the potential to standardise the measurement of cheer-leading and truth-seeking tendencies. Future researchers investigating bias and accuracy in intimate relationships should make use of this scale to make results more consistent and directly comparable to each other.

\section{Conclusion}

This research has important implications for the study of bias and accuracy in intimate relationships. First, it presents the development of a new psychometric measure that is both valid and reliable based on the given evidence. That is, there are individual differences in the motivation to seek the truth in, and analyse one's intimate relationships, or to see these relationships in an overly optimistic, positive light. Second, the findings provide preliminary evidence of the predictive ability of the scale, indicating its potential for future predictions. Finally, the creation of this scale provides a quick and simple tool for measuring the cheerleading and truth-seeking tendencies that promote biased and accurate judgements. Love, it seems, is both blind and rational, and this scale should help to investigate further the underlying motivational forces involved. 


\section{References}

Agnew, C. R., Loving, T. J., \& Drigotas, S. M. (2001). Substituting the forest for the trees: Social networks and the prediction of romantic relationship state and fate. Journal of Personality and Social Psychology, 81(6), 1042-1057.

Barelds-Dijkstra, P., \& Barelds, D. P. H. (2008). Positive illusions about one's partner's physical attractiveness. Body Image, 5(1), 99-108.

Bentler, P. M. (1995). EQS structural equations program manual. Encino, CA: Multivariate Software Inc.

Boyes, A. D., \& Fletcher, G. J. (2007). Metaperceptions of bias in intimate relationships. Journal of Personality and Social Psychology, 92(2), 286-306.

Campbell, L. (2005). Responses to verifying and enhancing appraisals from romantic partners: The role of trait importance and trait visibility. European Journal of Social Psychology, 35(5), 663-675.

Campbell, L., Lackenbauer, S. D., \& Muise, A. (2006). When is being known or adored by romantic partners most beneficial? Self-perceptions, relationship length, and responses to partner's verifying and enhancing appraisals. Personality and Social Psychology Bulletin, 32(10), 1283-1294.

Campbell, L., Simpson, J. A., Kashy, D. A., \& Fletcher, G. J. (2001). Ideal standards, the self, and flexibility of ideals in close relationships. Personality and Social Psychology Bulletin, $27(4), 447-462$. 
Collins, N. L., \& Feeney, B. C. (2000). A safe haven: An attachment theory perspective on support seeking and caregiving in intimate relationships. Journal of Personality and Social Psychology, 78(6), 1053-1073.

Eastwick, P. W., Finkel, E. J., Krishnamurti, T., \& Loewenstein, G. (2008). Mispredicting distress following romantic breakup: Revealing the time course of the affective forecasting error. Journal of Experimental Social Psychology, 44(3), 800-807.

Epley, N., \& Dunning, D. (2006). The mixed blessings of self-knowledge in behavioral prediction: Enhanced discrimination but exacerbated bias. Personality and Social Psychology Bulletin, 32(5), 641-655.

Fletcher, G. J., \& Boyes, A. D. (2008). Is love blind? Reality and illusion in intimate relationships. In J. Forgas, \& J. Fitness (Eds.), Social relationships: Cognitive, affective and motivational processes (pp. 101-114). Cambridge, UK: Cambridge University Press.

Fletcher, G. J., Danilovics, P., Fernandez, G., Peterson, D., \& Reeder, G. D. (1986). Attributional complexity: An individual differences measure. Journal of Personality and Social Psychology, 51(4), 875-884.

Fletcher, G. J., \& Kerr, P. S. (2010). Through the eyes of love: Reality and illusion in intimate relationships. Psychological Bulletin, 136(4), 627-658.

Fletcher, G. J., \& Kerr, P. S. (2013). Love, reality, and illusion in intimate relationships. In J. A. Simpson, \& L. Campbell (Eds.), The oxford handbook of close relationships (pp. 306320). New York, NY: Oxford University Press. 
Fletcher, G. J., Simpson, J. A., \& Boyes, A. D. (2006). Accuracy and bias in romantic relationships: An evolutionary and social psychological analysis. In M. Schaller, J. A. Simpson \& D. T. Kenrick (Eds.), Evolution and social psychology (pp. 189-209). New York, NY: Psychology Press.

Fletcher, G. J., Simpson, J. A., Campbell, L., \& Overall, N. C. (2013). The science of intimate relationships. West Sussex, UK: Wiley-Blackwell.

Fletcher, G. J., Simpson, J. A., \& Thomas, G. (2000). The measurement of perceived relationship quality components: A confirmatory factor analytic approach. Personality and Social Psychology Bulletin, 26(3), 340-354.

Fletcher, G. J., Simpson, J. A., Thomas, G., \& Giles, L. (1999). Ideals in intimate relationships. Journal of Personality and Social Psychology, 76(1), 72-89.

Fletcher, G. J., \& Thomas, G. (1996). Close relationship lay theories: Their structure and function. In G. J. Fletcher, \& J. Fitness (Eds.), Knowledge structures in close relationships (pp. 3-24). Mahwah, NJ: Erlbaum.

Fletcher, G. J., \& Thomas, G. (2000). Behavior and on-line cognition in marital interaction. Personal Relationships, 7(1), 111-130.

Fletcher, G. J., Fincham, F. D., Cramer, L., \& Heron, N. (1987). The role of attributions in the development of dating relationships. Journal of Personality and Social Psychology, 53(3), 481-489.

Fowers, B. J., Lyons, E., Montel, K. H., \& Shaked, N. (2001). Positive illusions about marriage among married and single individuals. Journal of Family Psychology, 15(1), 95-109. 
Gagné, F. M., \& Lydon, J. E. (2001). Mind-set and close relationships: When bias leads to (in)accurate predictions. Journal of Personality and Social Psychology, 81(1), 85-96.

Gagné, F. M., \& Lydon, J. E. (2003). Identification and the commitment shift: Accounting for gender differences in relationship illusions. Personality and Social Psychology Bulletin, 29(7), 907-919.

Gagné, F. M., \& Lydon, J. E. (2004). Bias and accuracy in close relationships: An integrative review. Personality and Social Psychology Review, 8(4), 322-338.

Geiss, S. K., \& O'Leary, K. D. (1981). Therapist ratings of frequency and severity of marital problems: Implications for research. Journal of Marital and Family Therapy, 7(4), 515520.

Haselton, M. G., \& Buss, D. M. (2000). Error management theory: A new perspective on biases in cross-sex mind reading. Journal of Personality and Social Psychology, 78(1), 81-91.

Karney, B. R., \& Bradbury, T. N. (1995). The longitudinal course of marital quality and stability: A review of theory, methods, and research. Psychological Bulletin, 118(1), 3-34.

Karney, B. R., \& Frye, N. E. (2002). "But we've been getting better lately": Comparing prospective and retrospective views of relationship development. Journal of Personality and Social Psychology, 82(2), 222-238.

Katz, J., \& Beach, S. R. H. (2000). Looking for love? Self-verification and self-enhancement effects on initial romantic attraction. Personality and Social Psychology Bulletin, 26(12), 1526-1539.

Kenny, D. A., \& Acitelli, L. K. (2001). Accuracy and bias in the perception of the partner in a close relationship. Journal of Personality and Social Psychology, 80(3), 439-448. 
Lackenbauer, S. D., Campbell, L., Rubin, H., Fletcher, G. J., \& Troister, T. (2010). The unique and combined benefits of accuracy and positive bias in relationships. Personal Relationships, 17(3), 475-493.

MacDonald, T. K., \& Ross, M. (1999). Assessing the accuracy of predictions about dating relationships: How and why do lovers' predictions differ from those made by observers? Personality and Social Psychology Bulletin, 25(11), 1417-1429.

Marsh, H. W., Balla, J. R., \& McDonald, R. P. (1988). Goodness-of-fit indicies in confirmatory factor analysis: The effect of sample size. Psychological Bulletin, 103, 391-410.

McNulty, J. K., O'Mara, E. M., \& Karney, B. R. (2008). Benevolent cognitions as a strategy of relationship maintenance: "Don't sweat the small stuff"....but it is not all small stuff. Journal of Personality and Social Psychology, 94(4), 631-646.

Mikulincer, M., Shaver, P. R., \& Pereg, D. (2003). Attachment theory and affect regulation: The dynamics, development, and cognitive consequences of attachment-related strategies. Motivation and Emotion, 27(2), 77-102.

Murray, S. L. (2001). Seeking a sense of conviction: Motivated cognition in close relationships. In G. J. Fletcher, \& M. S. Clark (Eds.), Blackwell handbook of social psychogy: Interpersonal processes (pp. 107-126). Oxford, UK: Blackwell.

Murray, S. L., \& Holmes, J. G. (2009). The architecture of interdependent minds: A motivationmanagement theory of mutual responsiveness. Psychological Review, 116(4), 908-928.

Murray, S. L., Holmes, J. G., Bellavia, G., Griffin, D. W., \& Dolderman, D. (2002). Kindred spirits? The benefits of egocentrism in close relationships. Journal of Personality and Social Psychology, 82(4), 563-581. 
Murray, S. L., Holmes, J. G., \& Griffin, D. W. (1996a). The benefits of positive illusions: Idealization and the construction of satisfaction in close relationships. Journal of Personality and Social Psychology, 70(1), 79-98.

Murray, S. L., Holmes, J. G., \& Griffin, D. W. (1996b). The self-fulfilling nature of positive illusions in romantic relationships: Love is not blind, but prescient. Journal of Personality and Social Psychology, 71(6), 1155-1180.

Murray, S. L., Holmes, J. G., \& Griffin, D. W. (2000). Self-esteem and the quest for felt security: How perceived regard regulates attachment processes. Journal of Personality and Social Psychology, 78(3), 478-498.

Murray, S. L., Rose, P., Holmes, J. G., Derrick, J., Podchaski, E. J., Bellavia, G., \& Griffin, D. W. (2005). Putting the partner within reach: A dyadic perspective on felt security in close relationships. Journal of Personality and Social Psychology, 88(2), 327-347.

Neff, L. A., \& Karney, B. R. (2005). To know you is to love you: The implications of global adoration and specific accuracy for marial relationships. Journal of Personality and Social Psychology, 88(3), 480-497.

Overall, N. C., Fletcher, G. J., \& Kenny, D. A. (2012). When bias and insecurity promote accuracy: Mean-level bias and tracking accuracy in couples' conflict discussions. Personality and Social Psychology Bulletin, 38(5), 642-655.

Overall, N. C., Sibley, C. H., \& Travaglia, L. K. (2010). Loyal but ignored: The benefits and costs of constructive communication behaviour. Personal Relationships, 17, 127-148.

Rosenburg, M. (1965). Society and the adolescent self-image. Princeton, NJ: Princeton University Press. 
Rusbult, C. E., Johnson, D. J., \& Morrow, G. D. (1986). Determinants and consequences of exit, voice, loyalty and neglect: Responses to dissatisfaction in adult romantic involvements. Human Relations, 39(1), 45-63.

Rusbult, C. E., \& Zembrodt, I. M. (1983). Responses to dissatisfaction in romantic involvements: A multidimensional scaling analysis. Journal of Experimental Social Psychology, 19(3), 274-293.

Rusbult, C. E., Zembrodt, I. M., \& Gunn, L. K. (1982). Exit, voice, loyalty, and neglect: Responses to dissatisfaction in romantic involvements. Journal of Personality and Social Psychology, 43(6), 1230-1242.

Simpson, J. A., Kim, J. S., Fillo, J., Ickes, W., Rholes, W. S., Oriña, M. M., \& Winterheld, H. A. (2011). Attachment and the management of empathic accuracy in relationship-threatening situations. Personality and Social Psychology Bulletin, 37(2), 242-254.

Simpson, J. A., Oriña, M. M., \& Ickes, W. (2003). When accuracy hurts, and when it helps: A test of the empathic accuracy model in marital interactions. Journal of Personality and Social Psychology, 85(5), 881-893.

Simpson, J. A., Rholes, W. S., \& Phillips, D. (1996). Conflict in close relationships: An attachment perspective. Journal of Personality and Social Psychology, 71(5), 899-914.

Swann, W. B., Jr., De La Ronde, C., \& Hixon, J. G. (1994). Authenticity and positivity strivings in marriage and courtship. Journal of Personality and Social Psychology, 66(5), 857-869.

Thomas, G., \& Fletcher, G. J. (2003). Mind-reading accuracy in intimate relationships: Assessing the roles of the relationship, the target, and the judge. Journal of Personality and Social Psychology, 85(6), 1079-1094. 


\section{Appendix}

\section{The Cheer-Leading and Truth-Seeking Scale}

When indicating your level of agreement with these questions, please think carefully about your CURRENT partner and relationship. Measured on a scale of 1 (strongly disagree) to 7 (strongly agree).

\section{Cheer-Leading Items}

I always see the bright side when thinking about my relationship

I avoid negative thinking about my partner

I try to think positively about my relationship

I actively try to think positively about my partner

I am an optimist about my relationship

I try to focus on the good things in my relationships

I prefer to focus on enjoying my partner's company, rather than dwell on bad things

I try to forget about negative things in my relationship

\section{Truth-Seeking Items}

I pay attention to changes in my partner's moods and feelings

I often think about how I would feel if I were in my partner's shoes

I try hard to understand my relationship

I try hard to explain problems in our relationship

I always want to know what my partner is thinking and feeling about me

I often analyse my relationship

I always like to know what my partner thinks about our relationship

I want to know the truth about our relationship 


\section{Shortened Attributional Complexity Scale}

Please answer each question as honestly and accurately as you can, but don't spend too much time thinking about each answer. Measured on a scale from 1 (strongly disagree) to 7 (strongly agree).

Item-total Correlation

I am very curious about human behaviour.

I prefer complex rather than simple explanations for people's behaviour.

I give much thought to how my own thinking works in the process of

understanding or explaining people's behaviour.

I often think about the different ways that people influence each other.

I seldom take people's behaviour at face value, and usually worry about

the inner causes for their behaviour, (e.g., attitudes, beliefs, etc.).

I think a lot about the influence that society has on my behaviour and personality.

I have often found that the basic cause for a person's behaviour is located far back in time. 


\section{Short Perceived Relationship Quality Components Inventory}

Rate each item with reference to how you think and feel about your current partner and romantic relationship with them, on a scale from 1 (not at all) to 7 (extremely).

How satisfied are you with your relationship?

How committed are you to your relationship?

How intimate is your relationship?

How much do you trust your partner?

How passionate is your relationship?

How much do you love your partner? 


\section{Rosenberg Self-Esteem Questionnaire}

Below is a list of statements dealing with your general feelings about YOURSELF. Rate the extent to which you agree with each item $(1=$ strongly disagree and $7=$ strongly agree $)$.

I feel that I'm a person of worth, at least on an equal plane with others.

I feel that I have a number of good qualities.

All in all, I am inclined to feel that I am a failure.

I am able to do things as well as most other people.

I feel I do not have much to be proud of.

I take a positive attitude toward myself.

On the whole, I am satisfied with myself.

I wish I could have more respect for myself.

I certainly feel useless at times.

At times I think I am no good at all. 


\section{Adult Attachment Questionnaire}

Rate each item below in reference to all your romantic close relationships in general, from 1 (strongly disagree) to 7 (strongly agree).

I find it relatively easy to get close to romantic partners

I'm not comfortable having to depend on romantic partners

I'm comfortable having my romantic partners depend on me.

I rarely worry about being abandoned by my romantic partners.

I don't like people getting too close to me.

I'm somewhat uncomfortable being too close to my romantic partners.

I find it difficult to trust my romantic partners completely.

I'm nervous whenever any of my romantic partners gets too close to me.

My romantic partners often want me to be more intimate than I feel comfortable being.

My romantic partners often are reluctant to get as close as I would like.

I often worry that my romantic partners don't really love me.

I worry about my romantic partners leaving me.

I often want to merge completely with my romantic partners, and this desire sometimes scares them away.

I am confident that my romantic partners would never hurt me by suddenly ending our relationship.

I usually want more closeness and intimacy than my romantic partners do.

The thought of being left by my romantic partners rarely enters my mind.

I am confident that my romantic partners love me just as much as I love them. 


\section{Problems in Relationships Scale}

All couples experience some difficulties or differences of opinion, even if they are only very minor ones. For each issue listed below, please rate the degree to which it is a source of difficulty or disagreement for you and your current partner (where $1=$ not a problem, and $7=$ major problem).

Communication

Unrealistic expectations of relationship

Showing affection

Lack of loving feelings

Sex

Amount of time spent together

Power struggles

Solving problems

Making decisions

Money management/finances

Household management

Conflict about gender roles
Serious individual problems

Affairs or infidelity

Relatives

Friends

Jealousy

Problems related to previous relationships

Employment/job

Recreation/leisure time

Alcohol or drugs

Physical abuse

Religion differences/conflict over values

Health problems

Children 


\section{Exit-Voice-Loyalty-Neglect Typology}

Please rate the following statements concerning the manner in which you respond to problems in your relationship ( $1=$ never do this, $4=$ sometimes do this, $7=$ constantly do this).

When my partner is upset and says something mean, I try to patch things up and solve the problem.

When my partner is angry with me and ignores me for awhile, I consider breaking up.

When my partner is rude or inconsiderate, I remain loyal and wait for things to get better.

When my partner behaves in an unpleasant or thoughtless manner, I do something else for awhile and avoid dealing with the situation.

When my partner is upset and says something mean, I feel so angry that I want to walk right out the door.

When my partner behaves in an unpleasant or thoughtless manner, I forgive my partner and forget about it.

When my partner is angry with me and ignores me for awhile, I get away for awhile and avoid dealing with the problem.

When my partner is rude or inconsiderate, I try to resolve the situation and improve conditions.

When my partner is upset and says something mean, I sulk and try to stay away from my partner for awhile.

When my partner is rude or inconsiderate, I begin to think about ending our relationship.

When my partner behaves in an unpleasant or thoughtless manner, I calmly discuss things with my partner.

When my partner is angry with me and ignores me for awhile, I hang in there and wait for my partner's mood to change - these times pass.

When my partner behaves in an unpleasant or thoughtless manner, I do something equally unpleasant in return. 
When my partner is angry with me and ignores me for awhile, I talk to my partner about what's going on, trying to work out a solution.

When my partner is upset and says something mean, I give my partner the benefit of the doubt and forget about it.

When my partner is rude or inconsiderate, I ignore the whole thing and try to spend less time with my partner. 